\title{
Further Characterization of the Effects of Alpha-1-Acid Glycoprotein on the Passage of Human Erythrocytes through Micropores
}

\author{
Hiroshi Maeda ${ }^{1, *}$, Tetsuo Morinaga ${ }^{1}$, Isao Mori² and Katsuhide Nishi ${ }^{2}$ \\ Departments of Microbiology ${ }^{1}$ and Pharmacology ${ }^{2}$, Kumamoto University \\ Medical School, 2-2-1, Honjo, Kumamoto City 860, Japan
}

\begin{abstract}
Effects of human alpha-1-acid glycoprotein (AG) on the passage of human red blood cell(s) (RBC) through membrane filters with micropores were examined in vitro. $\mathrm{RBCs}$, with a mean major diameter of $7.2 \mu \mathrm{m}$, that had been suspended at $1 \%$ in physiological phosphate-buffered saline (PBS), were filtered through membrane filters of various pore diameters under positive pressure. The percentages of cells that passed through the micropores and of cells hemolyzed during filtration were determined.

RBCs suspended in PBS did not pass through micropores that had an average pore diameter of $3 \mu \mathrm{m}$; instead hemolysis took place. Neither temperature nor applied pressure affected cell passage; but when AG at $0.1 \mathrm{mg} / \mathrm{ml}$ or above was added to an RBC-suspension, it promoted cell passage through the $3 \mu \mathrm{m}$ micropores and reduced the degree of hemolysis.

The effects of AG were dose dependent up to a concentration of $0.5 \mathrm{mg} / \mathrm{ml}$. The addition of AG to an RBC-suspension that contained $90 \%$ human serum had the same additive effects. Washing AG-treated RBCs with normal saline produced a marked decrease in cell passage through the $3 \mu \mathrm{m}$ pores.

Fluorescence antibody staining revealed that the exogenous AG was localized on the membrane surface of the RBCs. Our results suggest that the AG bound to the surface of the RBCs acts as a lubricant between the RBCs and the wall of the micropore; this would facilitate RBC-passage through the micropores.
\end{abstract}

Alpha-1-acid glycoprotein (AG), a normal serum constituent (75-100 mg/dl), with a molecular weight of approximately $40,000(6,12,13)$, has been reported to be an acute phase reactant increasing the plasma concentration in cases of pregnancy and inflammation and in cancer and other diseases $(6,13)$. Despite the reported pathological consequences, its biological function is not yet fully understood. Recently, attention has been focused on the physiological significance of the presence of AG in serum, and several reports concerning its function have been published (1-3, 9 , $11,14,18,19)$. Interestingly, AG has been reported to inhibit platelet aggregation $(2,14)$, lectin induced blastogenesis $(1,3)$ and influenza virus-induced hemagglutina-

Abbreviations used: AG; Alpha-1-acid glycoprotein, PBS; phosphate-buffered saline, RBC; red blood cell(s).

* To whom correspondence should be addressed. 
tion $(18,19)$. In a previous report, we showed that the addition of a small amount of AG to a human erythrocyte suspension facilitated the passage of the RBCs through artificial membrane filters with micropores having an average diameter smaller than that of an RBC, and we suggested a possible physiological role for AG in microcirculation (10).

The above facts appear to be related to the action of AG on the membrane surface of RBCs. Therefore, a series of experiments were designed to characterize in greater detail the effects of AG on RBC-passage through micropores. We used a new technique developed in our laboratory to evaluate cell-passage. In addition, the location of exogenously applied AG on erythrocytes was identified by a fluorescence antibody technique.

\section{MATERIALS AND METHODS}

Materials. The AG used was purified from pooled human sera by CM-cellulose column chromatography as described previously (20) or it was the gift of Professor Karl Schmid of Boston University (Mass, U.S.A.). The purity and identity of the AG were confirmed from its carbohydrate contents (hexose and sialic acid), elution $\mathrm{pH}$ from $\mathrm{CM}$-cellulose and by isoelectric focusing on thin-layer gel with ampholite, polyacrylamide gel electrophoresis with or without sodium dodecylsulfate and by Ouchterlony's immunodiffusion. Antitryptic activity also was confirmed as negative.

Human RBCs and sera were obtained from healthy donors (Types $\mathrm{O}$ and $\mathrm{B}$ ) and were tested by autologous combination in RBCs and serum unless purified AG was used. RBCs were obtained from blood treated with citrate then washed three times with Alsever's solution which consisted of $2.26 \mathrm{mM}$ citric acid, $27.2 \mathrm{mM}$ Na citrate, $71.8 \mathrm{mM} \mathrm{NaCl}$ and $113.9 \mathrm{mM}$ glucose at pH 6.7. We used only suspensions of washed RBCs at $1 \%(\mathrm{v} / \mathrm{v})$ to avoid the complicating effects of such other factors as the rheological properties of the concentrated cell-suspensions or pore occlusion during filtration $(5,8,15)$. The RBC suspension at a concentration of $1 \%$ was prepared by adding an appropriate volume of $0.01 \mathrm{M}$ phosphate buffered saline (PBS) (pH 7.0) to the packed erythrocytes.

Anti- $\alpha_{1}$ acid glycoprotein antibody and FITC-labeled anti-rabbit IgG. The antibody to human AG raised in rabbits was a gift from Japan Immunoresearch Inc., Takasaki, Japan. FITC-labeled fluorescent antibody, anti-rabbit-IgG (goat) was a gift from Meloy Laboratories, Springfield, Va, U.S.A. These antibodies were specific only to AG; there were no reactions with fibrinogen, hepatoglobin or alpha-1-antitrypsin.

Filtration apparatus. A diagram of the filtration apparatus used is shown in Fig. 1. Membrane filters (cellulose nitrate or cellulose acetate) with average pore-sizes of 3, 5 and $8 \mu \mathrm{m}$ were used (Sartorius Membrane Filter GmB., Göttingen, Germany; Millipore Membrane Ltd., Bedford, Mass, U.S.A.; Fuji Film Co., Tokyo, Japan). Filters from the same lot were used for one series of experiments because there was variation in pore-size among the different lot numbers, not very little variation in the same lot. A membrane filter with a diameter of 1.3 or $2.5 \mathrm{~cm}$ was placed on a plastic fitting attached to a 20-gauge needle, the upper end of the holder being fixed to the tip of a plastic injection syringe. RBC suspensions were taken into the syringe, then the cells were filtered through the membrane by setting a positive pressure ranging from 40 to $120 \mathrm{mmHg}$ for the reservoir to maintain the pressure under constant filtration. As the volume of the cell suspension in the syringe was very small in comparison to the volume in the reservoir, there was almost no change in pressure during filtration. The syringe was covered with a water-jacket through which temper- 


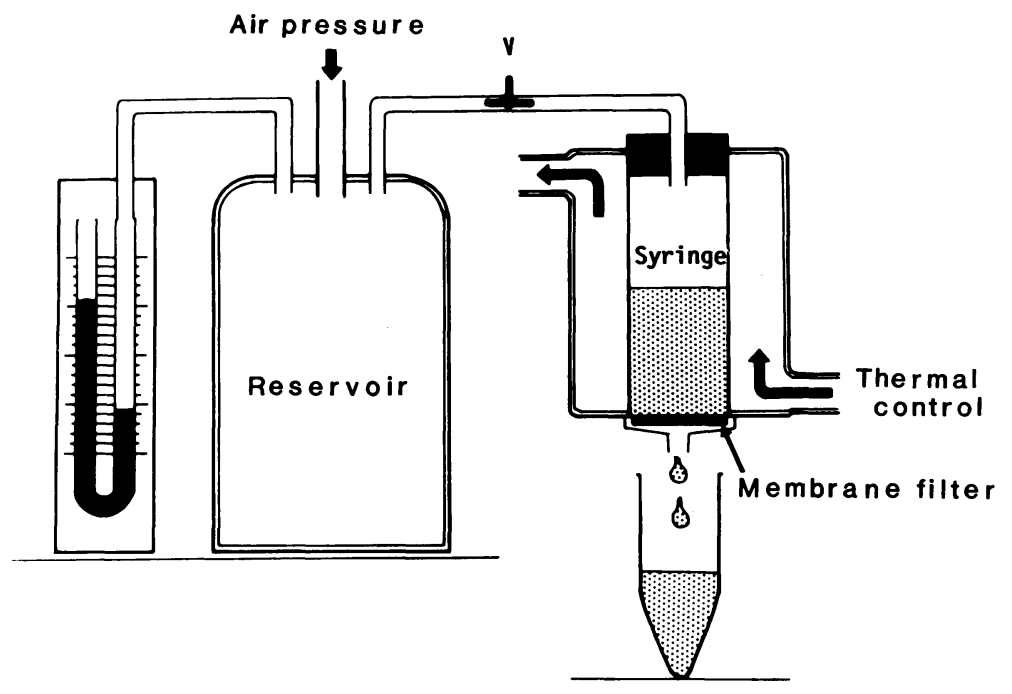

Fig. 1. Diagram of the experimental setup for RBC passage through micropores. The RBC suspension is placed in a syringe (dotted area), then a constant positive pressure monitored by a manometer (at left) is applied to the reservoir which is connected to the syringe by a glass tube via a three-way stop cock (V). The syringe is covered with a water-jacket through which temperaturecontrolled water is pumped at a constant rate.

ature controlled water was pumped at a constant rate to maintain a constant temperature during filtration.

Filtration procedures. AG dissolved in PBS was added to the RBC suspension, which then was incubated for $30 \mathrm{~min}$ at $37^{\circ} \mathrm{C}$. Subsequently, $1 \mathrm{ml}$ of the suspension was removed by syringe for filtration. The filtration process was begun by opening a valve (Fig. 1) connected to the reservoir in which a positive desired pressure had been maintained. The filtrate was recovered in a test tube and the amount of filtered RBCs was determined as follows.

A $0.5 \mathrm{ml}$ portion of the filtrate was centrifuged at $2,000 \mathrm{rpm}$ for $6 \mathrm{~min}$, then spectrophotometrical measurements of its supernatant were made at $420 \mathrm{~nm}$ to quantify the degree of hemolysis. The precipitated cells were hemolized by adding $3 \mathrm{ml}$ of distilled water and the amount determined spectrophotometrically. The total amount of RBCs filtered also was determined by this procedure. The ratios of the RBCs passed through the micropores and the number of hemolyzed cells relative to the total amount of the RBCs filtered were calculated. All filtrations were carried out at isotonic osmolarity unless otherwise specified.

Fluorescence antibody technique. To determine how exogenously applied AG interacts with $\mathrm{RBCs}$, we carried out an immune reaction with anti-AG rabbit serum $(\times 20$ dil.) and Ag-treated RBCs, followed by staining with FITC-labeled anti-rabbit-IgG (goat). Fluorescence microscopy then was used to observe the RBCs after they had been washed with PBS. In addition, smears of AG-treated RBCs placed on a slide glass were fixed with cold acetone before undergoing anti-AG antibody treatment. After treating the smears with anti-AG serum they were stained with FITC-labeled anti-rabbit IgG (goat). These prepared specimens were layered over with a drop of alkaline glycerol then covered with a cover slip and examined under fluorescence microscopy (Nikon Fluorophoto). 


\section{RESULTS}

Effects of temperature and pressure on the passage of RBCs through micropores. Experiments done previously showed that the number of RBCs that passed through a membrane filter, the degree of hemolysis and the filtration time varied with the size of the micropore and the pressure applied to the RBC suspension (10). Because the temperature and hydrostatic pressure used with an $\mathrm{RBC}$ suspension might affect the membrane fluidity as well as the deformability of RBCs, the effects of these factors on $\mathrm{RBC}$ passage through micropores were examined quantitatively, as reported here. Results are shown in Fig. 2.

When the RBC suspension was filtered through a membrane having an average pore diameter of $3 \mu \mathrm{m}$, no appreciable amounts of RBCs were detected in the filtrates at any temperature or pressure. But, the ratio of hemolyzed cells increased with the pressure applied at all temperatures. When membrane filters with pore diameters of 5 and $8 \mu \mathrm{m}$ were used, about 50 and $70 \%$ of the RBCs passed through the membranes. No temperature dependency was observed.

Results indicate that with our procedures neither temperature nor hydrostatic pressure affected RBC passage through the micropores. Therefore, a constant

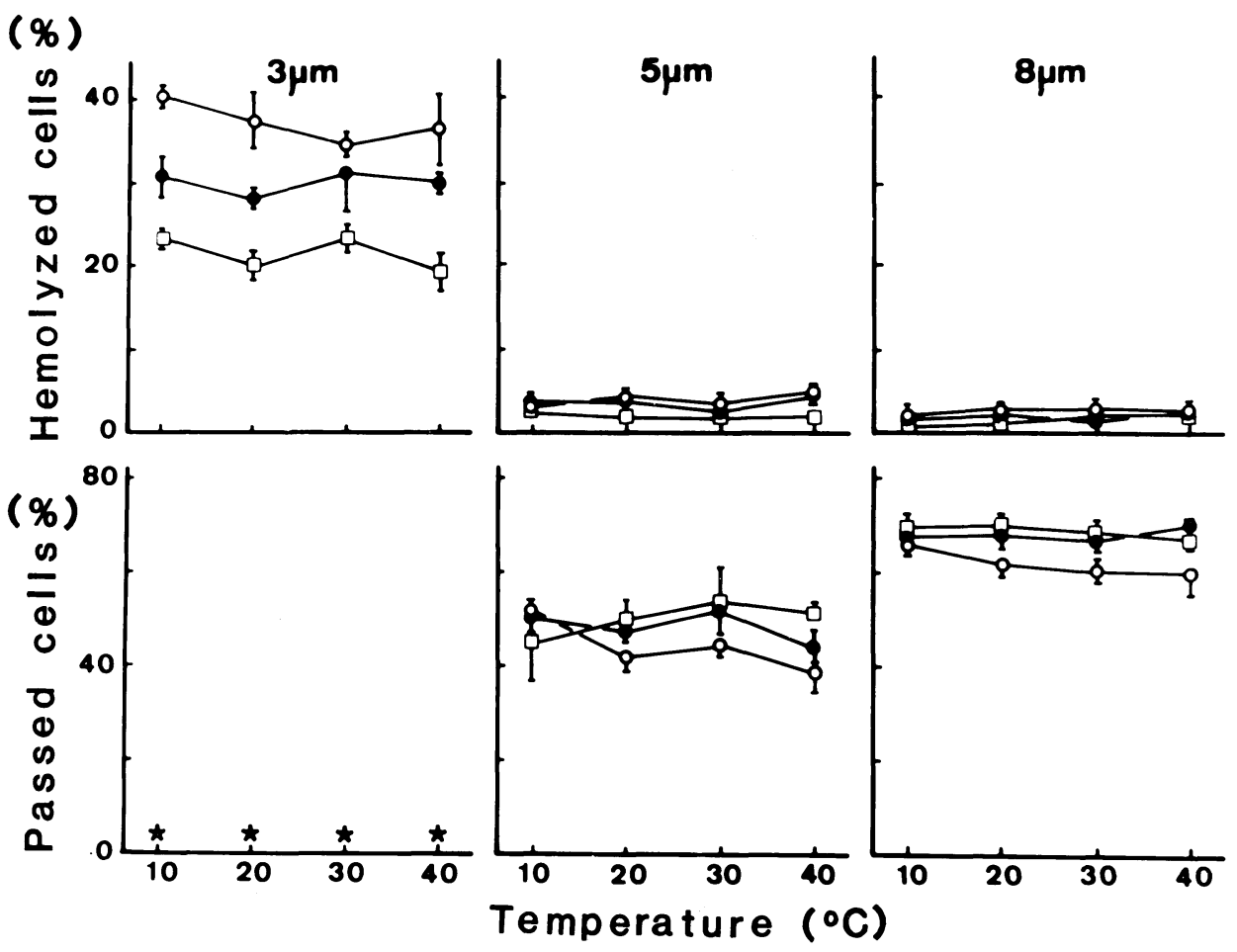

Fig. 2. Effects of temperature and pressure on RBC passage and hemolysis. RBCs were filtered through filters with different pore diameters $(3,5$ and $8 \mu \mathrm{m})$ at various temperatures and pressures. The percentages of RBC passage through the micropores and hemolyzed cells relative to the total number of RBCs filtered are shown (see Text). A constant pressure of $40(\square), 80(\bullet)$ or $120(\bigcirc)$ $\mathrm{mm} \mathrm{Hg}$ was applied. Two-days old RBCs were used. Asterisks indicate zero values. Each symbol represents the mean value and standard error of 5 experiments. Membrane filter: cellulose acetate. 
pressure of $80 \mathrm{mmHg}$ was applied to $\mathrm{RBC}$ suspensions at $37^{\circ} \mathrm{C}$ in the rest of the experiments. One advantage of using this pressure is that a relatively constant filtration time was obtained.

Effects of $A G$ on $R B C$ passage through micropores. When the concentration of the $\mathrm{AG}$ added to $\mathrm{RBC}$ suspensions was increased, the number of cells passing through a membrane filter with micropores having an average diameter of $3 \mu \mathrm{m}$ increased, whereas the number of hemolyzed cells decreased inversely with the concentration of $A G$ above $0.1 \mathrm{mg} / \mathrm{ml}$. Maximal effects were obtained at concentrations above $0.25 \mathrm{mg} / \mathrm{ml}$; a further increase in the $A G$ concentration above this value did not promote greater passage nor did prevent hemolysis (Fig. 3). Thus, the effects of AG were saturated at high AG concentrations.

Effects of $A G$ in the presence of serum. As stated previously, AG is a normal serum constituent $(0.75-1.0 \mathrm{mg} / \mathrm{ml})$ whose content is elevated in certain pathological states $(6,12,13)$. This raises two questions; whether this action is unique to $\mathrm{AG}$ among all the other components of blood serum, and whether AG added to an RBC suspension containing serum enhances RBC passage through micropores. To answer these questions, we suspended RBCs in PBS containing $0,10,30$ or $90 \%$ human serum then filtered the cells. At the same time, AG was added to each of these solutions, and the effect of its addition on RBC passage through micropores was examined.

In the presence of 10,30 or $90 \%$ human serum in the RBC-suspension, $10-15 \%$ of the RBCs passed through micropores having an average diameter of $3 \mu \mathrm{m}$, whereas the number of hemolyzed cells markedly decreased in comparison to the value for RBCs suspended in plain PBS. When AG was added to the same suspension (at final concentration of $0.5 \mathrm{mg} / \mathrm{ml}$ ), the RBCs that passed through the micropores was increased to about $35 \%$ in the presence of serum at 10 and $30 \%$. In the same cell suspension containing serum at $90 \%$ the percent of RBC passage through the micro-

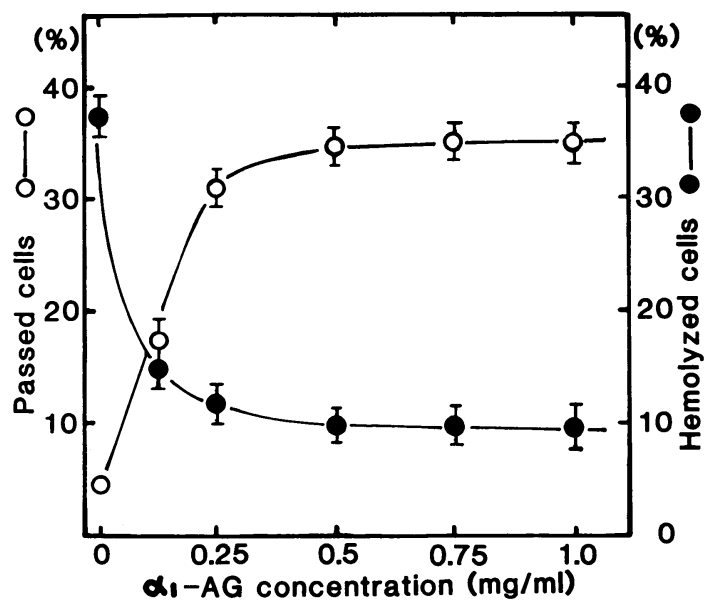

Fig. 3. Dose-response curves for the effects of AG on RBC passage through a membrane filtr with an average pore diameter of $3 \mu \mathrm{m}$ and for cells hemolyzed during filtration. The percent of RBCs passed through the micropores $(O)$ and of the hemolyzed cells $(\bullet)$ relative to the total number of RBCs suspended in PBS were determined as described in the Text. Two-days old RBCs were used. Each symbol represents the mean value and standard error of 5 experiments using membrane filters (cellulose acetate) from the same lot number with an average pore diameter of $3 \mu \mathrm{m}$. 
pores also increased when $A G$ was added, but the $A G$ effects were less pronounced than on RBCs suspended in plain PBS or in PBS containing 10 or $30 \%$ serum (Fig. 4, data of $30 \%$ not shown). The percent of hemolyzed cells was not changed by a further addition of $\mathrm{AG}$ to suspensions containing serum (more than $10 \%$ ).

These results indicate that $A G$ added to an $\mathrm{RBC}$-suspension, even in the presence of serum, facilitated the passage of RBCs through $3 \mu \mathrm{m}$ micropores. In contrast, hemolysis was prevented in the presence of serum whether or not AG was present. This means that another component (or components) of serum also has the antihemolytic property. But the endogenous AG in the serum per se and the rest of the constituents did not equal the added $\mathrm{AG}$ in facilitating $\mathrm{RBC}$ passage through the micropores.

Effects of $A G$ on the membrane filter and of washing the AG-treated cells. The facilitating effects of AG on RBC passage through $3 \mu \mathrm{m}$ micropores might have been due only to the coating the cellulose nitrate or acetate fibers of the membrane filters rather than to coating the RBCs; consequently, lubrication of the surfaces of the micropores would have resulted in the greater ease of passage of RBCs through the

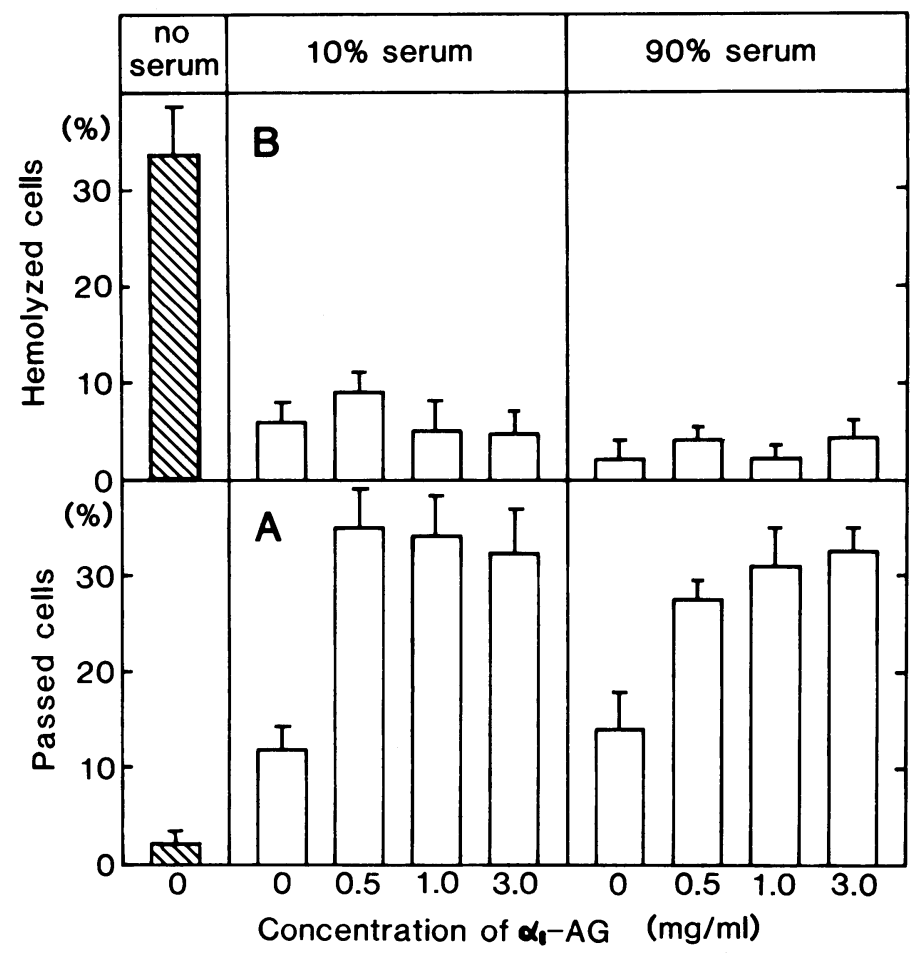

Fig. 4. Effects of AG on RBC passage through micropores and on hemolysis in the presence of serum. Hatched columns indicate the percent of RBCs passed through membrane filters with an average pore diameter of $3 \mu \mathrm{m}$ when neither AG nor serum (no serum) was present. Dose response relations for the effects when $A G$ was added to $\mathrm{RBC}$-suspensions containing 10 and $90 \%$ serum were obtained by calculating the percent of RBCs that passed through (A) and the percent of hemolyzed cells $(B)$ relative to the total number of RBCs filtered. Each column represents the mean value and standard error of 5 experiments. Membrane filters (cellulose acetate) with an average pore diameter of $3 \mu \mathrm{m}$ were used, but the lot numbers of the filters differed from those used in Fig. 2 and 3. Note that only a small percent of the RBCs without AG passed through the filter. Data of $30 \%$ serum were intermediate of 10 and $90 \%$ serum. 
micropores. If this were the case,treatment of membrane-micropores with AG before filtration of a plain RBC suspension would have appreciable effects on RBCpassage. To check this possibility, a membrane filter with micropores having an average diameter of $3 \mu \mathrm{m}$ was incubated for 30 min in PBS containing various concentrations of $A G$, then the RBC suspension without AG was filtered through it.

We found that none of the filters first treated with AG facilitated the passage of RBCs through their micropores. Therefore, in the next step of our experiments, we tested the effects of the removal of $A G$ from AG treated RBCs by washing the cells with plain PBS. For this purpose, RBCs initially were incubated in medium containing $0.5 \mathrm{mg} / \mathrm{ml}$ of $\mathrm{AG}$ for $30 \mathrm{~min}$ at $37^{\circ} \mathrm{C}$. These $\mathrm{AG}$ treated $\mathrm{RBCs}$ then were washed with the plain PBS by centrifugation, after which they were resuspended with gentle stirring for $5 \mathrm{~min}$ in plain PBS to repeat the washing. Results are shown in Fig. 5; the ratios of the number of RBCs passed through and the percentage of hemolyzed cells during filtration were plotted against the number of the washingprocedure.

About $40 \%$ of the RBCs treated with AG passed through the micropores, but the number of untreated RBCs that passed through the micropores was negligible (mean, $4.7 \%$ ). The ratios of $\mathrm{RBC}$ passage decreased with the number of washing; whereas, the percentage of hemolyzed cells increased inversely. These results indicate that AG, which might bind to the surface of the $\mathrm{RBC}$ and be reversibly removed, is responsible for easing the passage of RBCs through $3 \mu \mathrm{m}$ micropores. Thus, the removal of AG from the RBC by washing decreased the passage of RBCs.

$R B C s$-suspended in different medium osmolarities, and the effects of $A G$ on $R B C$ passage. The osmolarity of the medium is believed to affect the structural integrity of the RBS (16); it is assumed that RBCs suspended in a hypertonic solution become
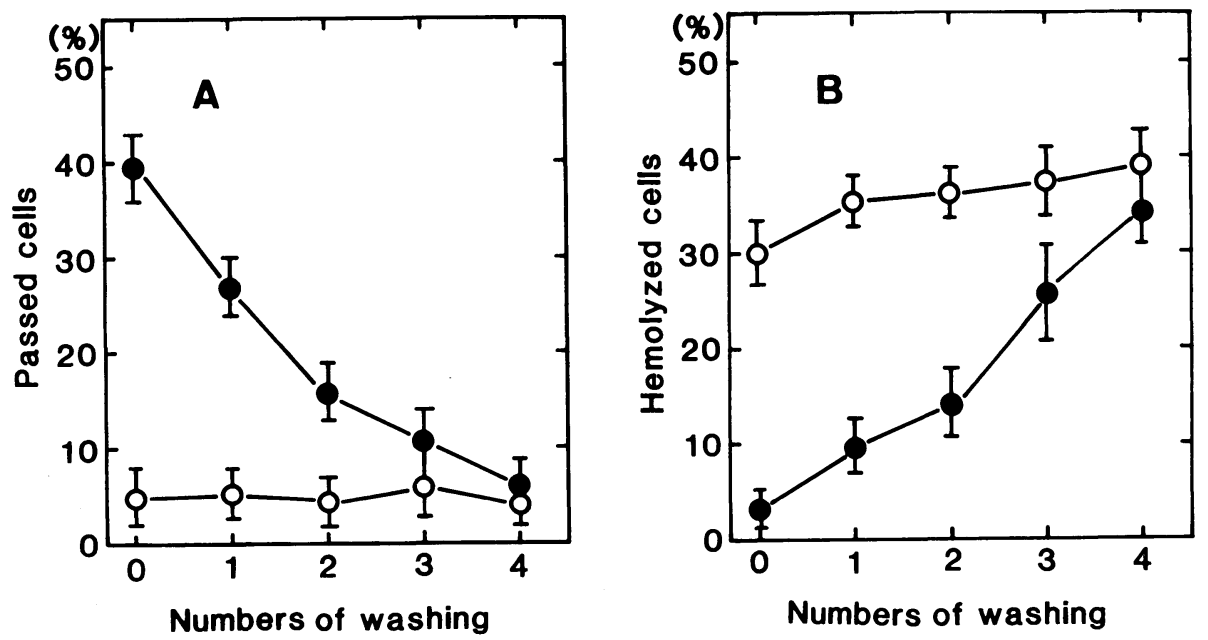

Fig. 5. Effects of washing AG-treated RBCs on cell passage through micropores and on hemolysis. The percentages of RBCs that passed through $3 \mu \mathrm{m}$ micropores (A) and of hemolyzed cells (B) after treated RBCs were washed with)plain PBS are shown. RBCs were prepared by washing fresh human erythrocytes 3 times at $20^{\circ} \mathrm{C}$. These cells were treated with an $\mathrm{AG}$ concentration of $0.5 \mathrm{mg} / \mathrm{ml}$ at $37^{\circ} \mathrm{C}$ for $30 \mathrm{~min}(\bullet)$, or left untreated $(\bigcirc)$. Each symbol represents the mean value and standard error of 5 experiments. 
more rigid than those in normal solution (17). Therefore, the effects of AG on the passage of RBCs whose physical properties would have been altered by changes in the osmolarity of the suspension medium were examined.

The osmolarity was changed by increasing the concentration of $\mathrm{NaCl}$ in $\mathrm{PBS}$ from 300 mOsm to 400 mOsm (Fig. 6). RBCs suspended in solutions of 300, 350 (isotonic) or $400 \mathrm{mOsm}$ could not pass through a membrane filter with $3 \mu \mathrm{m}$ micropores, but when membrane filters with larger micropores ( 5 and $8 \mu \mathrm{m})$ were used, passage increased with the increase in osmolarity. At $400 \mathrm{mOsm}$, only about $8 \%$ of the total number of RBCs passed through the $5 \mu \mathrm{m}$ micropores. Hemolysis, however, depended on pore-size rather than osmolarity; in general, the lower the passage of RBCs the greater the extent of hemolysis.

The addition of $\mathrm{AG}$ at a concentration of $0.5 \mathrm{mg} / \mathrm{ml}$ to $\mathrm{RBC}$ suspension at different osmolarities increased in the percent of RBC passage. This was clearest when membrane filters with average pore diameters of 5 and $8 \mu \mathrm{m}$ were used. About $55 \%$ of the RBCs passed through these micropores at $400 \mathrm{mOsm}$ in the presence of AG, whereas only $8 \%$ passed without AG. This was more pronounced with $8 \mu \mathrm{m}$ pores; $65 \%$ passage with AG and $40 \%$ without AG. Thus, AG markedly facilitated RBC passage through the micropores under a hypertonic condition, when cells presumably

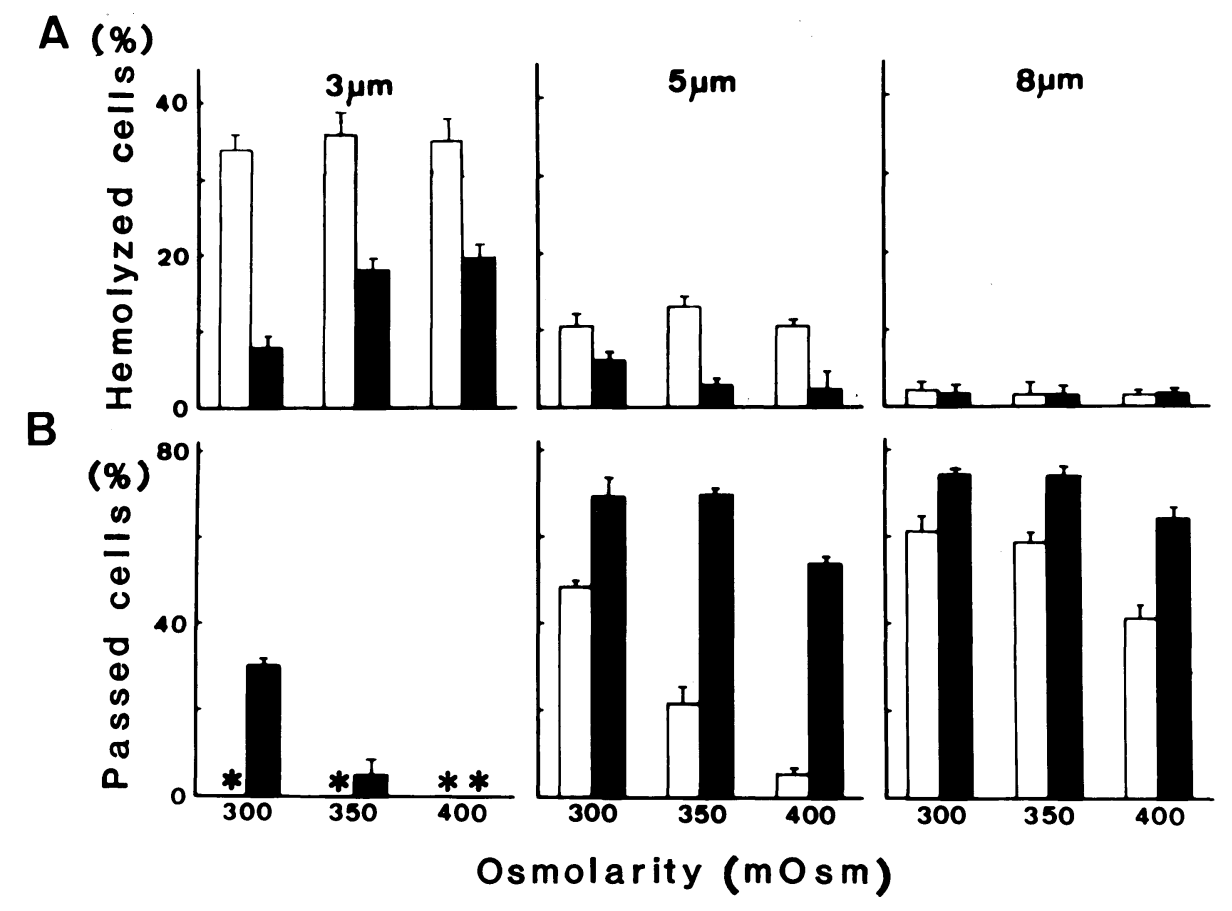

Fig. 6. Effects of osmolarity on RBC passage through micropores and on hemolysis in the presence, or absence, of AG. Membrane filters with different pore diameter $(3,5$ and $8 \mu \mathrm{m})$ were used. The percent of hemolyzed cells (A), and the percent of RBCs passed through micropores (B) in the absence (empty column) or presence (black column) of AG are shown for different pore sizes. RBCs were suspended in medium of different osmolarities. AG was added to the RBC-suspensions at $0.5 \mathrm{mg} / \mathrm{ml}$. Each column represents the mean value and standard error of 5 experiments. Asterisks show zero values. 
exhibit more viscous in cytoplasmic fluidity (17). The presence of AG also reduced hemolysis to a marked degree at various osmolarities.

Localization of $A G$ on AG-treated RBCs. To investigate the localization of AG in detail, AG-treated RBCs were examined under fluorescence microscopy after immunofluorescence staining. Fluorescence microscopy of RBCs that had been treated with $A G$ revealed $A G$ on the surface of the RBC (Fig. 7A). Its presence on AG-

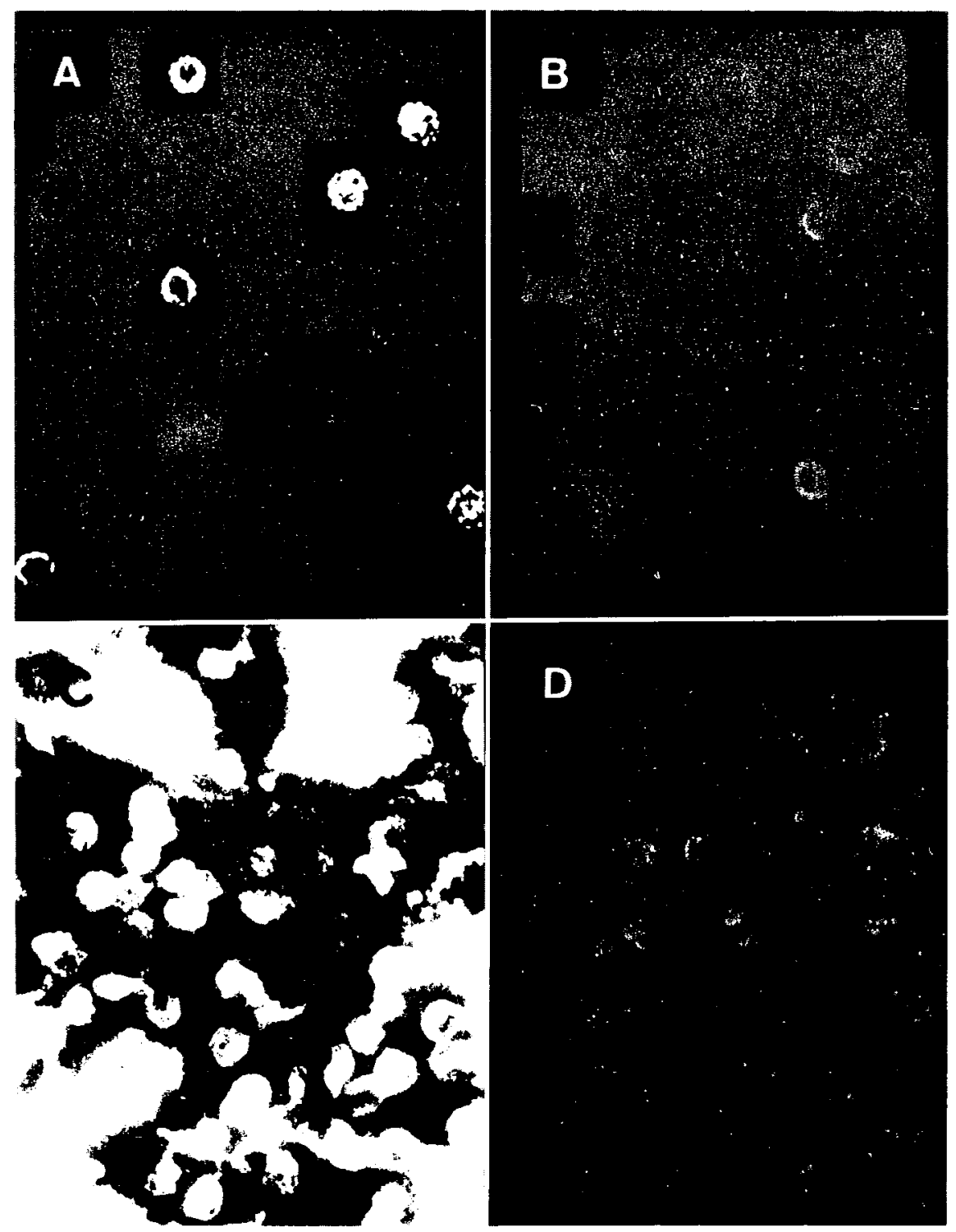

Fig. 7. Fluorescent antibody staining of RBCs and fluorescence microscopy. A: unfixed intact cells after AG-treatment. B: same as A, but untreated. C: RBC fixed with cold acetone after AGtreatment. The integrity of the cell membrane has been destroyed. D: same as C, but untreated. See text for details. 
treated RBCs also was confirmed after acetone-fixation (Fig. 7C). Fluorescence showed that AG mainly was located along the periphery of the cells. RBCs that had been treated with AG then washed 3 or 4 times with PBS did not emit fluorescence (not shown), evidence of the removal of AG from the RBC surface during the washing process.

\section{DISCUSSION}

The results of our filtration technique show that human RBCs with an average diameter of $7.2 \mu \mathrm{m}$ that are suspended in PBS do not pass through filters with micropores that have an average pore diameter of $3 \mu \mathrm{m}$, but that an increase in the pore diameter $(5 \mu \mathrm{m})$ allows limited passage of RBCs. Our results are consistent with the results of previous investigators who used the membrane filter method $(5,8,15)$. Hydrostatic pressure applied to RBC suspension was expected to affect the deformability of an RBC; the higher the pressure, the greater the cell deformation; this, in turn, would facilitate the passage of these cells through the micropores (16), if the deformability of the RBC alone is the important factor for the passage of RBCs through micropores. In our experiments, however, an increase in pressure did not markedly promote the passage of RBCs through $3 \mu \mathrm{m}$ micropores, instead it resulted in an increase in cell-disruption which led to hemolysis (Fig. 2, 3). This shows that even though cells were deformed to the maximal extent, they could not pass through the micropores. But, when $\mathrm{AG}$ was added to the $\mathrm{RBC}$ suspension, it promoted cell passage through the $3 \mu \mathrm{m}$ micropores (Fig. 3).

Two possible explanations can be offered: AG increases the deformability of RBCs, or AG acts as a lubricating film between the cells and the pore by coating the surface of the RBC membrane. Circumstantial evidence obtained in our experiments suggests that the latter possibility is more likely. As discussed above, the RBC would have been maximally deformed when forced to pass through the $3 \mu \mathrm{m}$ micropores under high pressure, but the maximally deformed cell still might be too large to pass through the pores, or friction between the cell membrane and the surface of the pore might not permit the passage of the RBC.

Under the same conditions, the AG added to the suspension, by binding to the surface of the RBC (as shown by fluorescent antibody staining, Fig. 7) would form a lublicating film on the surface of the RBC, that would reduce friction between the cells and pores. This speculation is supported by our results which show that RBCs suspended in a hypertonic solution (in which the cells become more rigid [17] ) passed through membrane filters with $5 \mu \mathrm{m}$ micropores more easily when AG was added (Fig. 6). Furthermore, the percentage of AG-treated RBCs that passed through the micropores decreased with the number of washings with plain PBS (Fig. 5).

The washing away of AG from the surface of the RBC membrane may have resulted in the loss of lubricating film. In fact, according to one report, the critical thickness of the lubricating film on the RBC is about $50 \mathrm{~nm}$, and when the thickness is less than this value there is an increase in friction (4).

The possibility that AG facilitates the deformation of the RBC appears, however, to be unlikely. In regard to the fluidity of the cell membrane, at temperatures above $30^{\circ} \mathrm{C}$ the membrane would be more fluid than at lower temperatures. Theevidence shown in Fig. 2 negates this possibility; neither facilitation of cell passage nor hemolysis was apparent between 10 and $40^{\circ} \mathrm{C}$ (Fig. 2). 
Endogenous AG and the other serum components had no facilitating effects on $\mathrm{RBC}$ passage through the micropores that were comparable to the effect of exogenously applied AG; only about $16 \%$ of the RBC, suspended in $90 \%$ serum passed through (Fig. 4). A supplement of AG to the serum, however, increased RBC passage through the micropores to a value similar to that obtained with AG in the plain PBS.

As to hemolysis, the presence of serum, even at $10 \%$, markedly protected $\mathrm{RBCs}$ from lysis and was as comparable to the effects of exogenous AG at $0.5 \mathrm{mg} / \mathrm{ml}$. Therefore, it is likely that serum component(s) other than AG per se would protect the membrane of the $\mathrm{RBC}$ from disruption when stress is applied to the cell. A further addition of $\mathrm{AG}$ to an $\mathrm{RBC}$-suspension containing serum did not prevent hemolysis to an extent beyond that which the presence of serum alone had done. This suggests that other serum component(s) may have occupied the binding sites on the surface of the RBC to which AG binds, thus preventing cell disruption.

We propose that an increase in the AG content of the serum above the normal value found in pathological conditions $(6,12,13)$ facilitates the passage of RBCs through capillaries, which would be a favorable situation for microcirculation. In fact, under pathological conditions of highly elevated fibrinolytic or clotting activity, antigen-antibody complex formation takes place which impedes blood circulation in the capillaries. But, an elevation of the AG in the plasma should facilitate microvascular passage of plasma cells. Thus, AG may function as an important factor in the homeostatic mechanisms that operate in microcirculation.

Acknowledgement. We thank Drs. K. Schmid and J. Verna and Mr. M. Adachi for supplying the various samples used.

\section{REFERENCES}

1. Bennett, M. and S. SChmid. Immunosuppression by human plasma $\alpha_{1}$-acid glycoprotein: Importance of the carbohydrate moiety. Proc. Natl. Acad. Sci. U.S.A. 77, 6109-6113, 1980

2. Costello, M., B.A. Fiedel and H. GewUrz. Inhibition of platelet aggregation by native and desialized alpha-1 acid glycoprotein. Nature 281, 677-678, 1970

3. Chiu, K.M., R.F. Mortensen, A.P. Osmand and H. Gewurz. Interaction of alpha-1 acid glycoprotein with immune system. I. Purification and effects upon lymphocyte responsiveness. Immunol. 32, 997-1005, 1977

4. Fitz-Gerald, J.M. Implication of a theory of erythrocyte motion in narrow capillaties. $J$. Appl. Physiol. 27, 912-919, 1969

5. Gregerson, M.I., C.A. Bryant, W.E. Hammerie, S. Usami and S. Chien. Flow characteristics of human erythrocytes through polycarbonate sieves. Science 157, 825-827, 1967

6. Jeanloz, R.W. $a_{1}$-Acid glycoprotein. in Glycoproteins, Vol. 5, Part A, ed. A. Gottschalk, Elsevier, Amsterdam, pp. 607-611, 1972

7. Kiesewetter, H., H. Schmid-Schoenhein, H. Radtke and G. Stolwerk. In vitro demonstration of collateral blood viscidation: Fllow measurements in a model of vascular networks. Microvasc. Res. 17, 372, 1979

8. Lingerd, P.S. Capillary pore rheology of erythrocytes. I. Hydroelastic behaviour of human erythrocytes. Microvasc. Res. 8, 53-63, 1974

9. Maeda, H., O. Murakami, M. Kann and I. Yamane. The growth stimulating effect of $\alpha_{1}$-acid glycoprotein in cells in culture. Proc. Soc. Exp. Biol. Med. 163, 223-227, 1980

10. Maeda, H., K. Nishi and I. Mori. Facilititating effects of $\alpha_{1}$-acid glycoprotein on the passage of erythrocytes through the membrane. Life Sci. 27, 157-161, 1980

11. NilsSen, I.M. and I. YAmashina. Effect of human $\alpha_{1}$-acid glycoprotein on blood coagulation. Nature 181, 711-712, 1958 
12. Schultz, H.E. and J.F. Hermanns. The plasma proteins. in Molecular Biology of Human Proteins Vol. 1, Elservier, Amsterdam, pp. 230-235, 1966

13. Schmid, K. $a_{1}$ Acid glycoprotein. in Plasma Proteins, Vol. 1, ed. F.W. Putnam, Academic Press, New York, pp. 184-228, 1975

14. SNYDer, S. and E.L. Coodly. Inhibition of platelet aggregation by $a_{1}$-acid glycoprotein. Arch Intern. Med. 136, 778-781, 1976

15. Schmid-Schoenhein, H. Factors promoting and preventing the fluidity of blood. in Microcirculation, eds. R.M. Effors, H. Schmid-Schoenhein and J. Ditzel, Academic Press, New York, pp. 249-266, 1981

16. Sobin, S.S. and H.M. Tremer. Three-dimensional organization of microvascular beds as related to function. in Microcirculation, Vol. 1, eds. G. Kally and B.M. Altura, Univ. Park Press. Baltimore, pp. 43-67, 1977

17. TsUDA, H. and H. MAEDA. Investigation of factors involved in the uptake velocity of fluorescein diacetate and intracellular fluorescence polarization value. I. Physiological aspects in lymphoblastoid cells. Cell Struct. Funct. 7, 165-175, 1982

18. Whitehead, P.H., T.H. Flewett, J.R. Foster and H.G. Sammos. Inhibition of influenza virus haemagglutination by polymerized orosomucoid. Nature 208, 915-916, 1965

19. WhiteheAD, P.H. and R.J. WINZLeR. Inhibition of viral hemagglutination by aggrgated orosomucoid. Arch. Biochem. Biophys. 126, 657-663, 1968

20. Yамамото, N., H. Maeda and H. Kanagawa. Ascitic fluid of malignant patients: Biochemical analysis and nature of growth promoting activity of cells in culture. Jap. J. Clin. Oncol. 6, 39-47, 1976

(Received for publication, August 27, 1984) 